\title{
Chronic Obstructive Pulmonary Disease Alters Immune Cell Composition and Immune Checkpoint Inhibitor Efficacy in Non-Small Cell Lung Cancer
}

\author{
Nicholas M. Mark ${ }^{1,2 *}$, Julia Kargl ${ }^{2,3 *}$, Stephanie E. Busch ${ }^{2}$, Grace H. Y. Yang ${ }^{2}$, Heather E. Metz ${ }^{2}$, Huajia Zhang ${ }^{2}$, \\ Jesse J. Hubbard ${ }^{2}$, Sudhakar N. J. Pipavath ${ }^{4}$, David K. Madtes ${ }^{1,2}$, and A. McGarry Houghton ${ }^{1,2,5}$ \\ ${ }^{1}$ Division of Pulmonary and Critical Care, and ${ }^{4}$ Department of Radiology, University of Washington, Seattle, Washington; ${ }^{2}$ Clinical \\ Research Division and ${ }^{5}$ Human Biology Division, Fred Hutchinson Cancer Research Center, Seattle, Washington; and ${ }^{3}$ institute of \\ Experimental and Clinical Pharmacology, Medical University of Graz, Graz, Austria
}

ORCID ID: 0000-0002-4244-1256 (N.M.M.).

\section{Abstract}

Rationale: Chronic obstructive pulmonary disease (COPD) and non-small cell lung cancer (NSCLC) are interrelated diseases with substantial mortality, and the pathogenesis of both involves aberrant immune functioning.

Objectives: To profile immune cell composition and function in patients with NSCLC and describe the effects of COPD on lung and tumor microenvironments.

Methods: We profiled resected lung and tumor tissue using flow cytometry and T-cell receptor sequencing in patients with and without COPD from a prospective cohort of patients undergoing resection of NSCLC. A murine cigarette smoke exposure model was used to evaluate the effect on pulmonary immune populations. A separate retrospective cohort of patients who received immune checkpoint inhibitors (ICIs) was analyzed, and their survival was quantified.
Measurements and Main Results: We observed an increased number of IFN- $\gamma$-producing $\mathrm{CD}^{+}$and $\mathrm{CD} 4{ }^{+}$(T-helper cell type 1 [Th1]) lymphocytes in the lungs of patients with COPD. In both humans and mice, increased Th17 content was seen with smoke exposure, but was not associated with the development or severity of COPD. COPD-affected lung tissue displayed increased Th1 differentiation that was recapitulated in the matching tumor sample. PD-1 (programmed cell death protein 1) expression was increased in tumors of patients with COPD, and the presence of COPD was associated with progression-free survival in patients treated with ICIs.

Conclusions: In patients with COPD, Th1 cell populations were expanded in both lung and tumor microenvironments, and the presence of COPD was associated with longer progression-free intervals in patients treated with ICIs. This has implications for understanding the immune mediators of COPD and developing novel therapies for NSCLC.

Keywords: COPD; immune checkpoint inhibitor; lung cancer; tumor microenvironment

(Received in original form April 20, 2017; accepted in final form September 20, 2017)

*These authors contributed equally to this work.

Supported by National Cancer Institute/NIH grant R01 188341, Fred Hutchinson Cancer Research Center Seattle Translational Tumor Research, and European Union grant EU-FP7-PEOPLE-2012-IOF 331255.

Author Contributions: N.M.M.: analyzed mouse and human flow-cytometry and T-cell receptor $\beta$ (TCR- $\beta$ ) sequencing data; designed, performed, and analyzed all clinical research; and wrote the manuscript. J.K.: designed, performed, and analyzed all human flow-cytometry experiments and TCR- $\beta$ sequencing, and edited the manuscript. S.E.B.: designed, performed, and analyzed all mouse flow-cytometry experiments. G.H.Y.Y.: performed and assisted with human flow-cytometry experiments. H.E.M.: performed and analyzed mouse flow-cytometry experiments. H.Z.: assisted with analysis of flow-cytometry data. J.J.H.: assisted with design and Institutional Review Board approval of clinical research, and assisted with clinical data abstraction. S.N.J.P.:

analyzed all patient imaging and scored the extent of emphysema present. D.K.M.: supervised the design and collection of clinical data. A.M.H.: supervised the design and performance of all experiments, reviewed all data, and wrote and edited the manuscript.

Correspondence and requests for reprints should be addressed to A. McGarry Houghton, M.D., Fred Hutchinson Cancer Research Center, 1100 Fairview Avenue N., D4-100, Seattle, WA 98109-1024. E-mail: houghton@fhcrc.org.

This article has an online supplement, which is accessible from this issue's table of contents at www.atsjournals.org.

Am J Respir Crit Care Med Vol 197, Iss 3, pp 325-336, Feb 1, 2018

Copyright @ 2018 by the American Thoracic Society

Originally Published in Press as DOI: 10.1164/rccm.201704-07950C on September 21, 2017

Internet address: www.atsjournals.org 


\section{At a Glance Commentary}

\section{Scientific Knowledge on the}

Subject: Chronic obstructive pulmonary disease (COPD) and non-small cell lung cancer (NSCLC) are interrelated diseases associated with substantial mortality. The pathogenesis of both diseases involves aberrant immune functioning. Immune checkpoint inhibitors block PD1 (programmed cell death protein 1)/PDL1 (programmed cell death protein ligand 1) signaling and improve survival in a subset of patients with NSCLC.

\section{What This Study Adds to the}

Field: In a large cohort of patients undergoing resection of NSCLC, we identified a novel phenotype of increased T-helper cell type $1 \mathrm{CD}^{+}$ lymphocyte differentiation in patients with COPD, which was also present in the tumor microenvironment. In a separate cohort of patients receiving immune checkpoint inhibitors, we found that the presence of COPD was associated with increased progressionfree survival. These important immune and clinical observations may influence future trials and NSCLC therapy.

Chronic obstructive pulmonary disease (COPD) affects more than 20 million Americans and constitutes the third leading cause of death in the United States. Lung cancer is the leading cause of cancer mortality both in the United States and worldwide, accounting for more lives lost each year than colon, breast, prostate, and pancreatic cancers combined. COPD is caused, at least in part, by immune-mediated airway remodeling and destruction of lung parenchyma, instigated by tobacco smoke exposure in susceptible individuals (1). Evasion of the host immune response plays an important role in the pathogenesis of non-small cell lung cancer (NSCLC), and COPD is a well-established risk factor for the development of NSCLC (2). Only a minority of people exposed to cigarette smoke will develop COPD; however, patients with COPD have a much greater risk of developing NSCLC, even after correcting for cigarette smoke exposure (3). Furthermore, the risk of developing and dying from NSCLC increases progressively with the extent of
COPD, as defined by either the degree of airflow obstruction (4-9) or the severity of radiographic emphysema (8-12). Despite numerous epidemiological studies documenting the link between COPD and NSCLC, the mechanistic basis for this association remains poorly defined.

Our understanding of the immune processes underlying COPD and NSCLC is evolving (13). These diseases were initially thought to be driven exclusively by innate inflammation and associated proteinase burden; however, subsequent studies have also demonstrated key roles for the adaptive immune system. Beginning with the seminal work by Hogg and colleagues (14), important roles for $\mathrm{CD}^{+}$and $\mathrm{CD}^{+} \mathrm{T}$ cells in COPD have been established. Further interrogation of lymphocyte populations has yielded more insights, suggesting that differentiation of $\mathrm{CD}^{+}{ }^{+} \mathrm{T}$ cells into T-helper cell type 1 (Th1) (15) and Th17 (16-18) lineages, production of IFN- $\gamma$ by CD8 ${ }^{+}$T cells (19), increased lymphocyte expression of immune checkpoints (PD-1 [programmed cell death protein 1] and PD-L1 [programmed cell death protein ligand 1]) $(20,21)$, and the expansion of clonal populations of lymphocytes $(22,23)$ are associated with COPD development and progression.

Emerging evidence suggests that the abundance and subtype of tumorinfiltrating lymphocytes have important prognostic implications for NSCLC (24). Specifically, increased numbers of Th1 $\mathrm{CD}^{+}{ }^{+} \mathrm{T}$ cells and IFN- $\gamma$-producing $\mathrm{CD} 8^{+}$ lymphocytes in tumors are associated with an improved response to immune therapies and a better prognosis (25). Novel therapies have enhanced favorable immune responses in patients with NSCLC for therapeutic benefit, and abrogation of PD-1/PD-L1 signaling with immune checkpoint inhibitors (ICIs) was shown to substantially improve survival in a subset of patients with NSCLC (26-28). Although it is clear that smokers are more likely to respond to these immune therapies (29), the impact of COPD on intratumoral immunity and treatment responses to ICIs has not been addressed. Given the increasing use of ICIs in the treatment of NSCLC, understanding the interconnections between COPD and NSCLC will be necessary to optimize treatment and improve outcomes for patients with both COPD and NSCLC.

To better elucidate the complex interactions between COPD and NSCLC, we used a comprehensive flow-cytometry panel to determine immune cell content and function in tumor and non-tumoradjacent lung tissue from patients undergoing lung cancer resection, the majority of whom had COPD. We used this cohort to identify the immune cell populations associated with COPD severity (using the Global Initiative for Chronic Obstructive Lung Disease [GOLD] stage), the interrelationship of lung tissue and lung tumor immunity in matched patients, and the impact of COPD on immune cell content and function within the tumor microenvironment. Lastly, we examined a retrospective cohort of patients with NSCLC treated with ICIs to determine the impact of COPD on outcomes. The results show that Th1-mediated immunity permeates the COPD and NSCLC microenvironments, and that the presence of COPD is associated with favorable treatment responses to immune checkpoint inhibition.

\section{Methods}

\section{Patient Cohorts and Study Approval}

This study used two distinct patient cohorts. Cohort 1 was a previously described prospective cohort composed of patients undergoing curative-intent surgical resection of suspected NSCLC (30). Clinical parameters, including smoking history and pulmonary function, were abstracted. Cohort 2 was a retrospective cohort of patients with NSCLC who had been treated with ICIs. Clinical parameters as well as overall survival (OS) and progression-free survival (PFS) data were abstracted. Institutional review board approval was obtained for both cohorts.

\section{COPD/Emphysema Severity}

COPD severity was staged by degree of airflow obstruction (GOLD stage) (31) and by degree of emphysema on chest computed tomography (CT) scan (modified Goddard score) (32).

\section{Tissue Processing and Flow Cytometry}

Fresh tumor and nonadjacent lung tissue were processed into a single-cell suspension, and the single-cell suspension was stained with a panel of 23 antibodies as previously described (30). 


\section{Murine Cigarette Smoke Exposure Model}

Female C57/BL6j mice were exposed to tobacco smoke for 24 weeks as previously described (33), with unexposed, agematched, female littermates used as controls. Flow cytometry was performed as previously described (34). All experiments were approved by the Institutional Animal Care and Use Committee.

\section{Statistical Analysis}

A two-tailed Student's $t$ test was used for comparisons of two groups, and ANOVA was used for comparisons of three or more groups. For multiple comparisons, a Bonferroni-Dunn correction was applied. Survival was compared using KaplanMeyer analysis. The log-rank test was used to compare survival or event-free survival between groups, and Cox proportional hazards modeling was used for univariate and multivariate analyses. A $P$ value $<0.05$ was considered significant.
For additional details, see the METHODS section in the online supplement.

\section{Results}

\section{Patient Cohort and Flow Cytometry}

We generated a prospective cohort of $n=73$ patients undergoing curative-intent resection of suspected primary lung cancer. Most of the patients in cohort 1 $(89 \%)$ were former or current smokers and the majority $(61.1 \%)$ of them had COPD based on the GOLD definition of airflow obstruction. Most of the patients with CT imaging had some degree of emphysema by modified Goddard score (67.7\%). The tumor immune profiles as a function of histologic subtype have previously been reported (30). Other notable clinical features of cohort 1 are provided in Table 1. Using a detailed flow-cytometry panel, we comprehensively assessed the immune cell composition of lung tissue obtained from patients with and without COPD, as defined by the presence of airflow obstruction. Compared with smokers without COPD, patients with COPD had similar numbers of $\mathrm{CD} 45^{+}$and myeloid cells. However, patients with COPD had an increased fraction of $\mathrm{CD}^{+}(P=0.0079)$, $\mathrm{CD}^{+}(P=0.0103)$, and $\mathrm{CD} 8{ }^{+}$cells $(P=$ 0.0178 ; Figure 1; Table E1 in the online supplement). Furthermore, we observed a significant increase in $\mathrm{CD}^{+} \mathrm{T}$ cell content depending on the degree of airflow obstruction (ANOVA, $P=0.0443$ ), with the largest increase identified in COPD GOLD stage 1 patients $(P=0.0074$; Figure 1$)$. The increased number of $\mathrm{T}$ cells in smokers without COPD compared with smokers with GOLD 1 COPD consisted of both $\mathrm{CD}^{+}(P=0.0067)$ and $\mathrm{CD} 8^{+}(P=0.0260)$ lineages. Among smokers, there were no significant differences that corresponded to the degree of airflow obstruction in polymorphonuclear leukocytes, macrophages, natural killer cells, natural killer T cells, or B cells (Figure 1 and Table E1). The entire flow-cytometric dataset was

Table 1. Characteristics of Cohort 1

\begin{tabular}{|c|c|c|c|c|c|c|}
\hline & $\begin{array}{l}\text { Never } \\
\text { Smokers }\end{array}$ & $\begin{array}{c}\text { Smokers without } \\
\text { COPD }\end{array}$ & $\begin{array}{l}\text { GOLD I } \\
\text { COPD }\end{array}$ & $\begin{array}{l}\text { GOLD II } \\
\text { COPD }\end{array}$ & $\begin{array}{l}\text { GOLD III } \\
\text { COPD }\end{array}$ & $\begin{array}{l}P \text { Value } \\
\text { (ANOVA) }\end{array}$ \\
\hline \multicolumn{7}{|l|}{ Demographics } \\
\hline Subjects, $n$ & 9 & 19 & 14 & 25 & 5 & \\
\hline Sex, male, $n(\%)$ & $4(44.4 \%)$ & $6(31.6 \%)$ & $9(64.3 \%)$ & $15(60.0 \%)$ & $3(60.0 \%)$ & 0.0921 \\
\hline Age, yr & $67.0 \pm 7.2$ & $65.1 \pm 7.9$ & $71.6 \pm 8.7$ & $66.9 \pm 9.4$ & $65.4 \pm 6.2$ & 0.3892 \\
\hline \multicolumn{7}{|l|}{ Race, $n(\%)$} \\
\hline White & 5 (55.6\%) & 18 (94.7\%) & 12 (85.7\%) & $22(88.0 \%)$ & $5(100 \%)$ & 0.4329 \\
\hline Hispanic & & & $1(7.1 \%)$ & & 0 & \\
\hline Asian & $4(44.4 \%)$ & $1(5.3 \%)$ & 0 & $2(8.0 \%)$ & 0 & \\
\hline Native American & 0 & 0 & $1(7.1 \%)$ & $1(4.0 \%)$ & 0 & \\
\hline \multicolumn{7}{|l|}{ Smoking status } \\
\hline Current smoker, $n(\%)$ & N/A & 5 (26.3\%) & $5(35.7 \%)$ & 7 (28.0\%) & $1(20 \%)$ & 0.1151 \\
\hline Former smoker, $n(\%)$ & $\mathrm{N} / \mathrm{A}$ & $14(73.7 \%)$ & $9(64.3 \%)$ & $18(72.0 \%)$ & $4(80 \%)$ & \\
\hline Pack-years & $\mathrm{N} / \mathrm{A}$ & $31.4 \pm 15.4$ & $34.0 \pm 28.9$ & $40.1 \pm 27.5$ & $29.0 \pm 28.6$ & 0.0128 \\
\hline \multicolumn{7}{|l|}{ Spirometry } \\
\hline $\begin{array}{l}\text { FEV }_{1}, \% \text { predicted } \\
\text { FEV/FVC ratio }\end{array}$ & $\begin{array}{l}84.3 \pm 15.9 \\
0.68 \pm 0.11\end{array}$ & $\begin{array}{l}94.4 \pm 17.4 \\
0.74 \pm 0.05\end{array}$ & $\begin{array}{l}88.9 \pm 9.4 \\
0.62 \pm 0.05\end{array}$ & $\begin{array}{l}69.7 \pm 8.7 \\
0.59 \pm 0.10\end{array}$ & $\begin{array}{l}43.7 \pm 2.6 \\
0.60 \pm 0.11\end{array}$ & $\begin{array}{l}<0.001 \\
<0.001\end{array}$ \\
\hline \multicolumn{7}{|l|}{ Malignancy type, $n(\%)$} \\
\hline Adenocarcinoma & $6(66.7 \%)$ & $16(84.2 \%)$ & 9 (64.3\%) & $17(68.0 \%)$ & $4(80 \%)$ & 0.2049 \\
\hline Squamous cell & 0 & $2(10.5 \%)$ & $5(35.7 \%)$ & $6(24.0 \%)$ & $1(20 \%)$ & \\
\hline SCLC & 0 & 0 & 0 & $1(4.0 \%)$ & 0 & \\
\hline Other ${ }^{\star}$ & $3(33.3 \%)$ & $1(5.3 \%)$ & 0 & $1(4.0 \%)$ & 0 & \\
\hline \multicolumn{7}{|l|}{ Malignancy stage, $n(\%)$} \\
\hline I & $5(55.6 \%)$ & $16(84.2 \%)$ & $8(57.1 \%)$ & 17 (68.0\%) & 2 (40.0\%) & 0.5838 \\
\hline II & 0 & $3(15.8 \%)$ & $5(35.7 \%)$ & 0 & $1(20.0 \%)$ & \\
\hline III & $2(22.2 \%)$ & 0 & 2 (14.3\%) & 3 (12.0\%) & $2(20.0 \%)$ & \\
\hline IV & 0 & 0 & 0 & $1(4.0 \%)$ & 0 & \\
\hline
\end{tabular}

Definition of abbreviations: COPD = chronic obstructive pulmonary disease; GOLD = Global Initiative for Chronic Obstructive Lung Disease; SCLC = small cell lung cancer.

Data are presented as mean \pm SD unless otherwise indicated. $P$ values $<0.05$ are set in bold for emphasis. $n=72$ patients.

*Other cancers included adenosquamous carcinoma $(n=1)$, adenocarcinoma in situ $(n=1)$, carcinoid tumor $(n=1)$, metastatic renal cell carcinoma $(n=1)$, and sarcomatoid carcinoma $(n=1)$. 
A
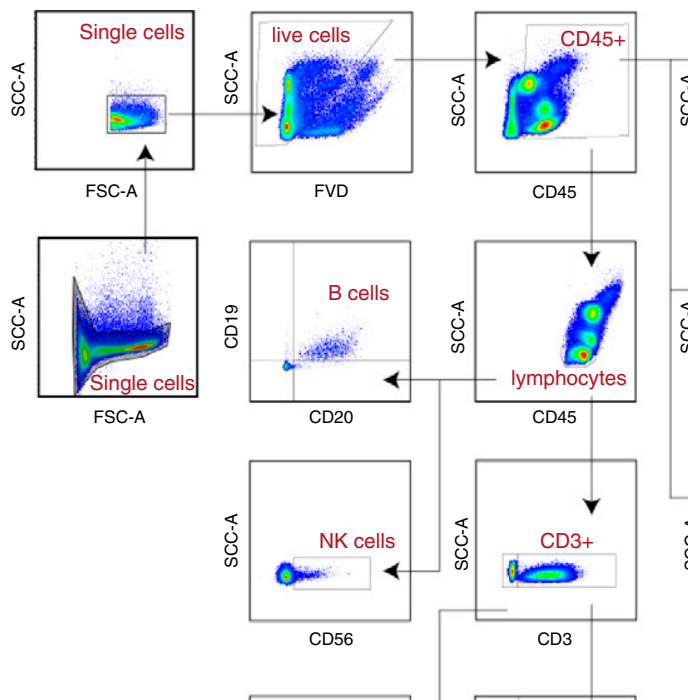

4
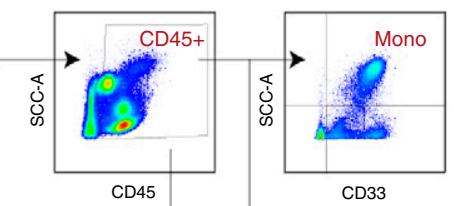

CD33
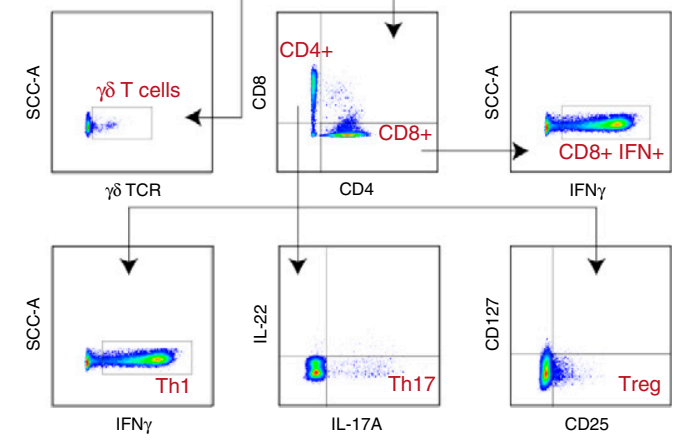

H
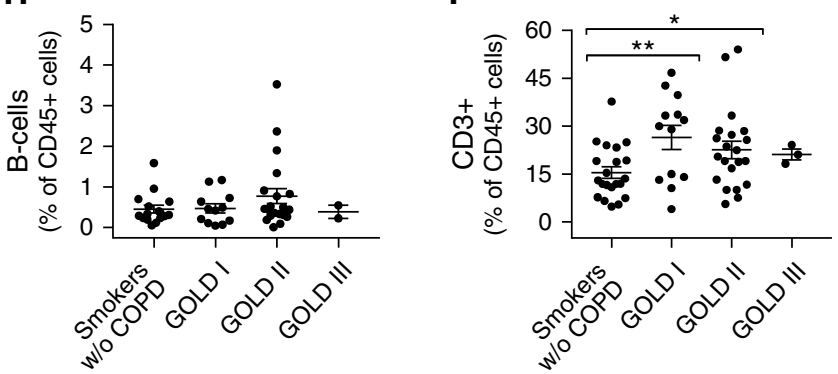

B

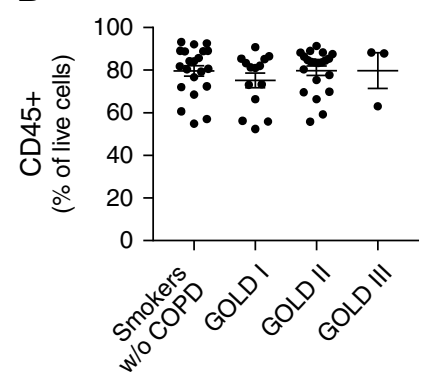

D

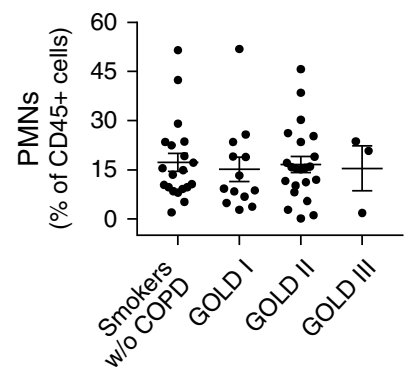

$\mathbf{F}$

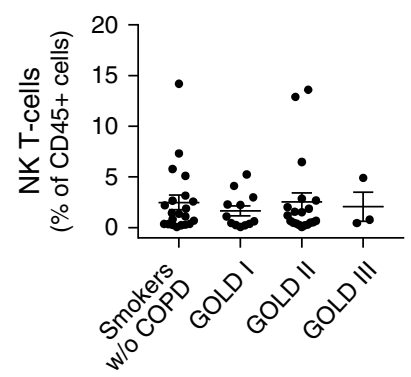

J

C

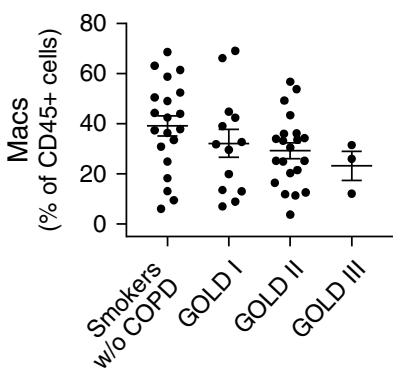

E

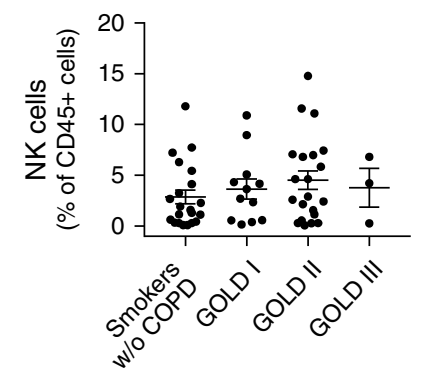

G

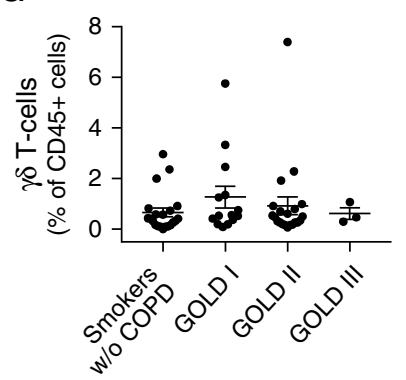

K

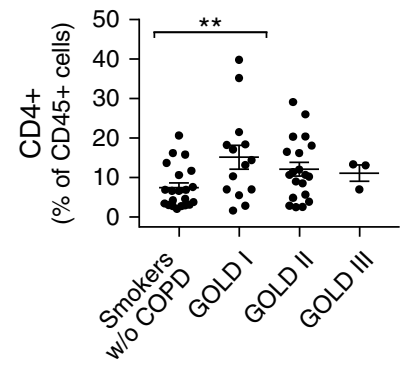

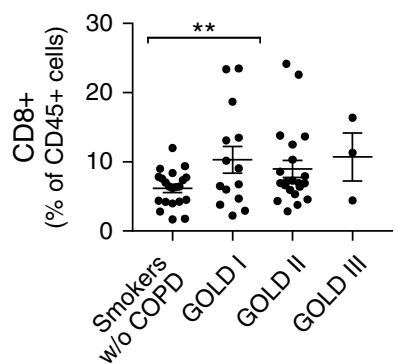

Figure 1. Analysis of immune cell population by degree of airflow obstruction. (A) Cell gating strategy to identify immune populations. Cell content by Global Initiative for Chronic Obstructive Lung Disease (GOLD) stage for $(B)$ CD45 ${ }^{+}$cells, $(C)$ macrophages, $(D)$ polymorphonuclear leukocytes (PMNs), $(E)$ natural killer (NK) cells, $(F)$ NK T cells, $(G) \gamma \delta$ T cells, and $(H)$ B cells. (I) CD3 ${ }^{+}$T cells, including both CD4 ${ }^{+}(J)$ and CD8 ${ }^{+}(K)$ lineages. All are expressed as the percentage of $C D 45^{+}$cells, except for $B$, which is the percentage of live cells; $n=59$ patients. Bars denote the mean \pm SEM. ${ }^{\star} P<0.05 ;{ }^{*} P<0.01$. COPD = chronic obstructive pulmonary disease; FSC-A = forward scatter area; FVD = fluorescent viability dye; $\gamma \delta \mathrm{TCR}=\gamma \delta \mathrm{T}-\mathrm{cell}$ receptor; $\mathrm{mac}=$ macrophage; $\mathrm{mono}=$ monocyte; SCC-A = side scatter area; Th1 = T-helper cell type 1; Treg = regulatory $\mathrm{T}$ cell; $\mathrm{w} / \mathrm{O}=$ without .

also stratified by emphysema severity (measured by modified Goddard score on chest imaging), which provided results similar to those obtained in the analysis by GOLD stage (Figure E1).
After phorbol myristate acetateionomycin stimulation, we used an intracellular cytokine-staining panel to analyze $\mathrm{CD} 4^{+}$differentiation into specific Th1, Th17, and regulatory $\mathrm{T}$ cell (Treg) programs. There was a notable increase in Th1-polarized $\mathrm{CD} 4^{+}$lymphocytes in patients with COPD (Table E1), particularly in those with GOLD 1 COPD (Figure 2A) compared with smokers 
A

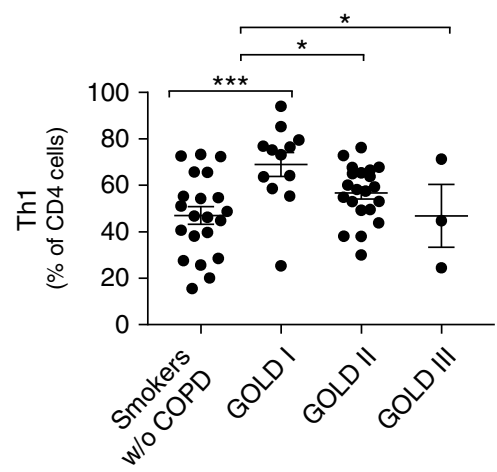

B

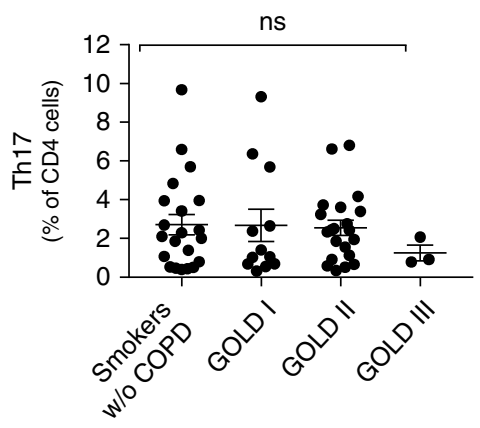

C

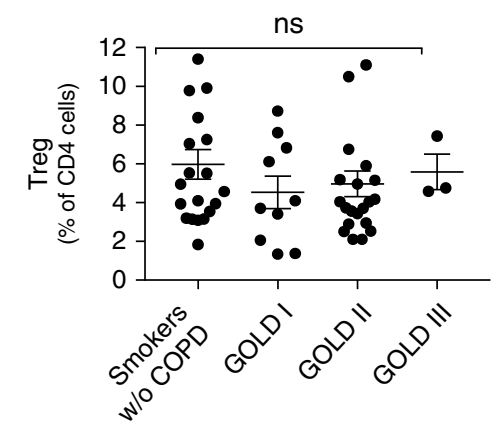

D

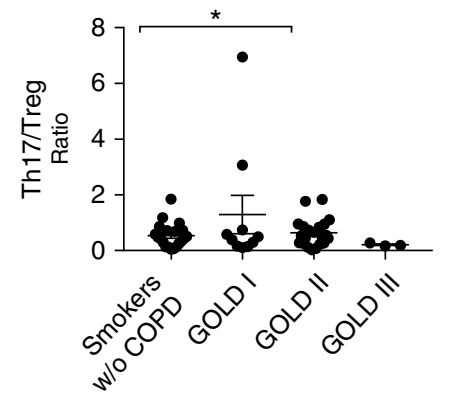

E

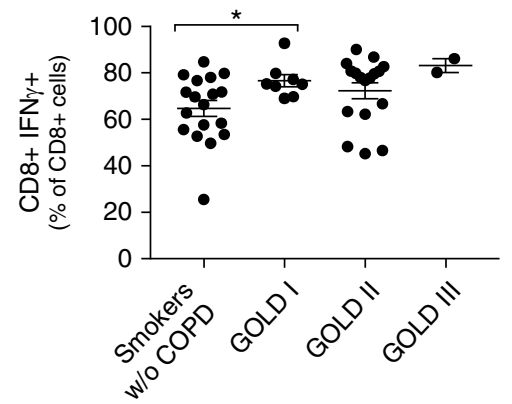

$\mathbf{F}$

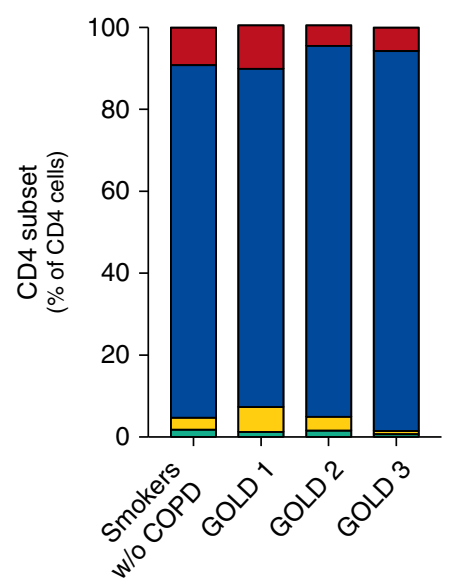

G

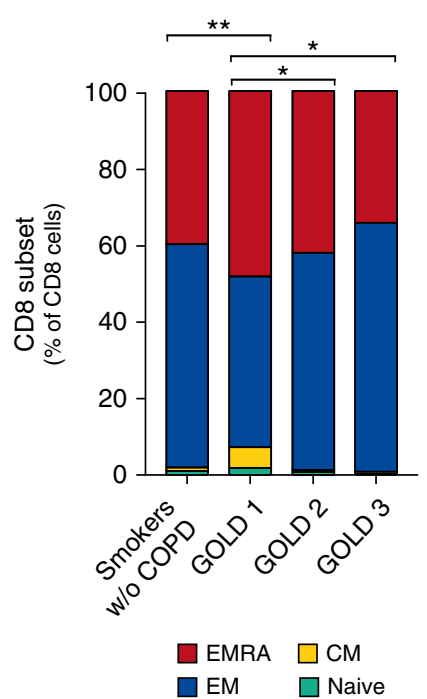

Figure 2. Altered $T$ cell differentiation with airflow obstruction. $C D 4^{+}$lineages were examined by degree of airflow obstruction and included (A) T-helper cell type 1 (Th1), $(B)$ Th17, $(C)$ Treg, and $(D)$ the ratio of Th17 to Tregs. (E) Expression of IFN- $\gamma$ by $\mathrm{CD}^{+}$lymphocytes by degree of airflow obstruction $(n=57$ patients). Expression of CD45RA and CCR7 was used to evaluate the differentiation of (F) CD4 ${ }^{+}$and $(G)$ $\mathrm{CD}^{+}$cells into EMRA, EM, CM, and naive populations. $n=56$ patients. Bars denote the mean $\pm \mathrm{SEM}$. ${ }^{\star} P<0.05 ;{ }^{\star \star} P<0.01 ;{ }^{\star \star \star} P<0.001 . \mathrm{CM}=$ central memory; $\mathrm{COPD}=$ chronic obstructive pulmonary disease; EM = effector memory; EMRA = effector memory cells re-expressing CD45RA; GOLD = Global Initiative for Chronic Obstructive Lung Disease; ns = not significant; Treg = regulatory $T$ cell; $w / O=$ without.

without COPD $(P=0.0005)$. We did not, however, identify changes in Th17 or Treg differentiation (Figures 2B-2D). We found that IFN- $\gamma$ production was increased in $\mathrm{CD}^{+}$lymphocytes in GOLD stage 1 airflow obstruction compared with controls (Figure 2E). We assessed the effector/memory status of the $\mathrm{CD} 4^{+}$and $\mathrm{CD}^{+}$populations using cell-surface staining for CCR7 and CD45RA expression on unstimulated cells (no phorbol myristate acetate-ionomycin) (35). There was an increase in the number of $\mathrm{CD} 8{ }^{+}$effector memory cells re-expressing CD45RA $\left(\mathrm{CD}^{+}{ }^{+} \mathrm{CCR}^{-}{ }^{-} \mathrm{CD}^{2} 5 \mathrm{RA}^{+}{ }^{+}\right.$[EMRA] lymphocytes in GOLD stage 1 disease $(P=$ $0.0058)$ and a corresponding decrease in the number of effector memory $\left(\mathrm{CD}^{+}{ }^{+} \mathrm{CCR}^{-}\right.$ $\mathrm{CD}_{45 \mathrm{RA}^{-}}{ }^{-} \mathrm{EM}$ ) lymphocytes (Figures $2 \mathrm{~F}$ and $2 \mathrm{G}$ ). Among both $\mathrm{CD}^{+}$and $\mathrm{CD}^{+}$cells, there were no significant changes in the fraction of naive or central memory lymphocytes.

Because other groups have reported antigen-driven immune responses in COPD, we performed DNA sequencing of the T-cell receptor $\beta$ (TCR- $\beta$ ) gene locus for a subset of patients ( $n=34$ patients). We analyzed the frequency of each TCR- $\beta$ $\mathrm{V}$ allele rearrangement (Figure E2) and found several changes in allele frequency associated with smoking status, airflow obstruction, and emphysema severity. However, after correction for multiple comparisons, none of these findings remained significant (Tables E2, E3, and $\mathrm{E} 4$ ).

Given the relevance of immune checkpoint receptor expression in patients with COPD and NSCLC, we quantified PD1 expression on $\mathrm{CD}^{+}$and $\mathrm{CD} 8{ }^{+}$cells, and PD-L1 expression on myeloid cells. We found no significant difference in PD-1 expression in lung tissue of patients with COPD versus nonsmokers or smokers without COPD, nor did we find trends in PD-1 expression corresponding to the degree of airflow obstruction or emphysema (Figures E3 and E4).

\section{Th17 Differentiation Is Associated with Smoking Status}

Although there was no relationship between Th17 differentiation and the presence of airflow obstruction, smoking status was associated with Th17 differentiation. We observed an increase in the fraction of Th17 cells in former smokers $(P=0.0068$; Figure 3D) and current smokers $(P=$ $0.0005)$ as compared with never smokers. 
A

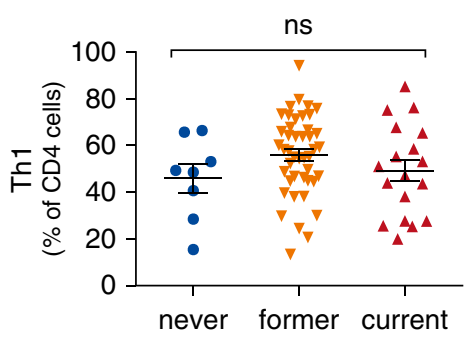

D

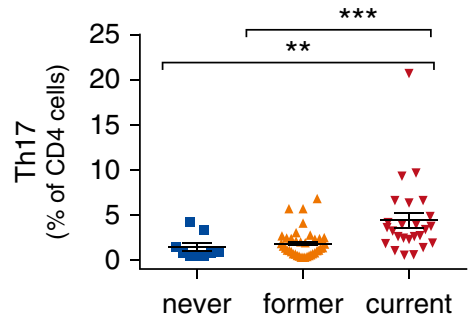

B

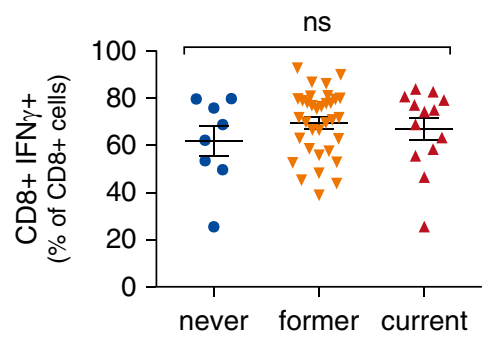

E

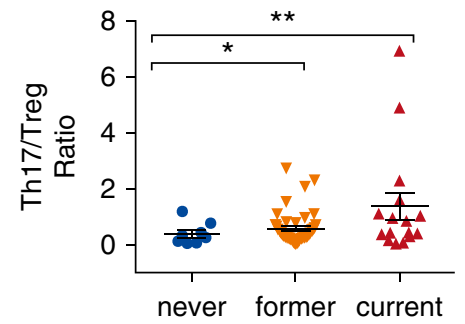

C

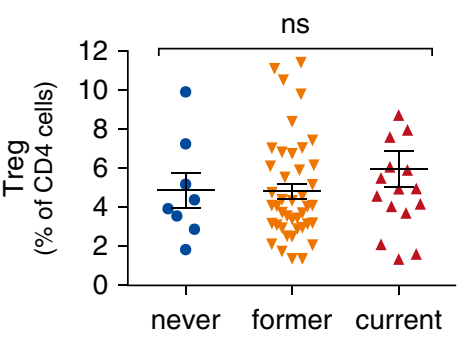

$\mathbf{F}$

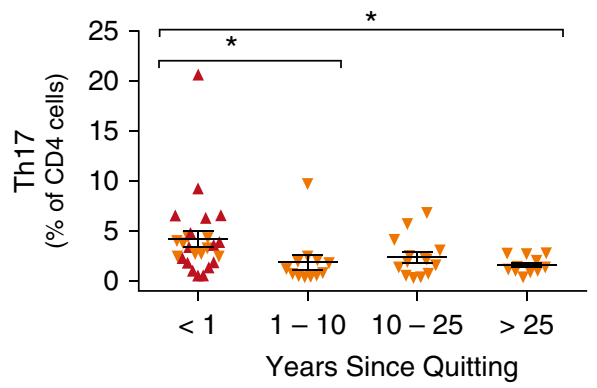

G

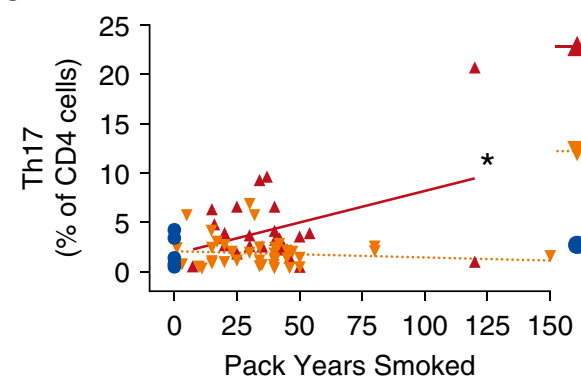

I

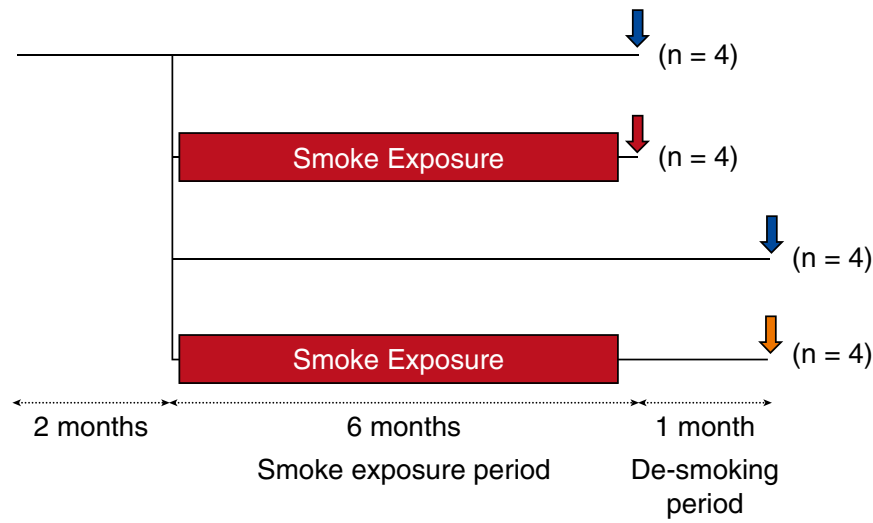

Current smokers (mean $=4.47 \pm 0.86, \mathrm{n}=24)$ $\left(R^{2}=0.165, p=0.0439\right)$

$\checkmark$.... Former smokers $($ mean $=1.85 \pm 0.24, \mathrm{n}=40)$ $\left(R^{2}=0.011, p=0.5348\right)$

Never smokers

(mean = 1.44 $\pm 0.46, \mathrm{n}=9$ )
H

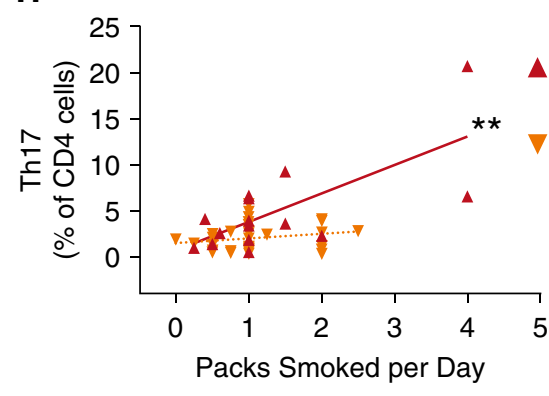

J

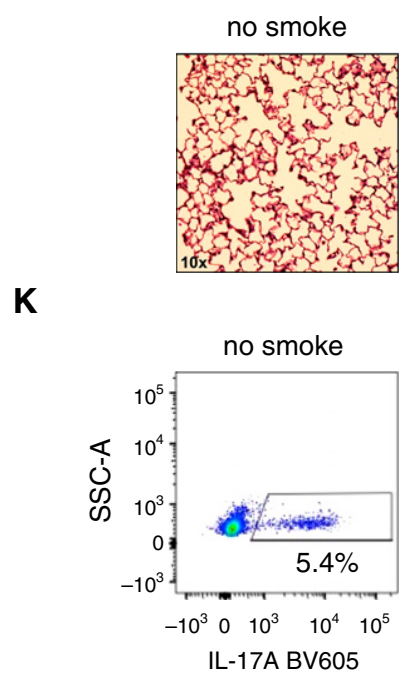

Current Smokers $\left(R^{2}=0.5004, p=0.0032\right)$

$\checkmark$ Former Smokers $\left(R^{2}=0.0389, p=0.2046\right)$

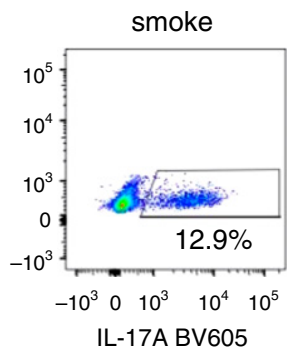

Figure 3. T-helper cell type 17 (Th17) differentiation in humans and mice is associated with cigarette smoke exposure. T cell subsets were quantified by smoking status, including $(A)$ Th1, $(B)$ CD8 ${ }^{+}$IFN- $\gamma^{+}$cells, $(C)$ Tregs, $(D)$ Th17 cells, and $(E)$ the Th17/Treg ratio. Th17 was quantified by the total number of pack-years smoked $(G)$, number of packs smoked per day $(H)$, and years since quitting $(F) . n=57$ patients for all groups. ( () C57BL6 mice $(n=4$ mice in each group) were exposed to cigarette smoke or sham as shown diagrammatically. Each group was compared with the non-smoke-exposed littermates of the same age as controls. Red arrow: smoke exposed; yellow arrow: smoke exposed then desmoked; blue arrow: not smoke exposed (control). The data are expressed relative to the control 
$\mathbf{L}$

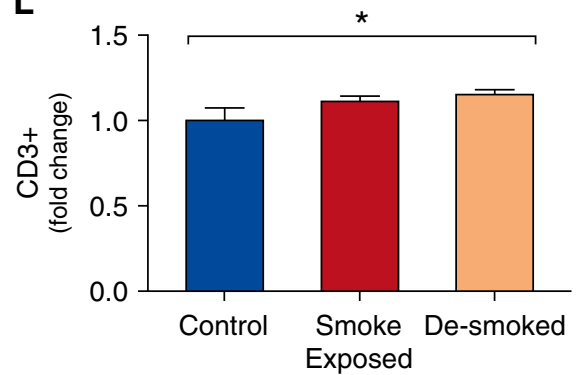

Figure 3. (Continued).

Smoking status did not appear to affect Th1 or Treg polarization or production of IFN- $\gamma$ by $\mathrm{CD} 8^{+}$lymphocytes (Figures $3 \mathrm{~A}-3 \mathrm{C}$ ).

We identified a correlation between the fraction of Th17 cells and the total packyears smoked (Figure 3G), as well as between the fraction of Th17 cells and the number of packs per day smoked (Figure $3 \mathrm{H}$ ). There was also a significant decline in Th17 with time after smoking cessation (Figure 3F), suggesting both a temporal and a dose-dependent relationship between smoke exposure and Th17 differentiation. Other than a small increase in Th1 differentiation (Figure E2I), there were no significant correlations between the dose of cigarette smoke exposure (pack-years) and the immune cell composition of the lung (Figure E5). Because this finding suggests that Th17 immunity in COPD may track with smoking status as opposed to disease severity, we used a murine cigarette smoke exposure model in an attempt to distinguish between the two. In this model, exposure to cigarette smoke for 6 months led to the development of airspace enlargement (Figures 3I and 3J). Flowcytometry analysis of mouse lung demonstrated increased numbers of $\mathrm{CD} 4^{+}$ T cells after smoke exposure (Figure 3L), with a significant increase in $\mathrm{CD}^{+}$and Th17 differentiation (Figures $3 \mathrm{M}$ and $3 \mathrm{~N}$ ), similar to the findings in humans. We found that the fraction of Th17 cells increased in smoke-exposed mice compared with non-smoke-exposed controls (Figures $3 \mathrm{~K}$ and $3 \mathrm{~N}$ ). Furthermore, in mice as in humans, this increase in Th17 was significantly attenuated when the mice were
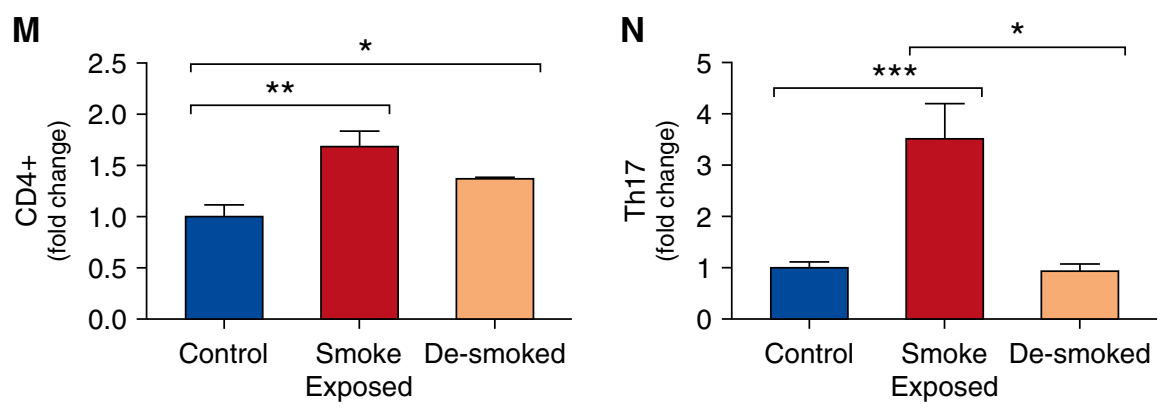

removed from smoke exposure ("desmoked") for 1 month (Figure $3 \mathrm{~N}$ ), again suggesting a temporal relationship between smoke exposure and Th17 differentiation.

\section{Th1 Immunity Links Lung and Tumor Immunity}

To elucidate the relationship between the immune effectors in COPD and the immune response to malignancy, we compared the immune cell composition of the resected tumors with that of nonadjacent lung parenchyma. In addition to increased numbers of $\mathrm{CD}^{+}$and $\mathrm{CD} 8^{+}$lymphocytes in tumors of patients with COPD (Figure 4B), there was a significant correlation between the fraction of $\mathrm{CD} 4{ }^{+}$ $\left(R^{2}=0.1172 ; P=0.0139\right)$ and $\mathrm{CD}^{+}\left(R^{2}=\right.$ $0.1317 ; P=0.0089$ ) lymphocytes in the lung parenchyma and within adenocarcinomas (Figures 4A, 4C, and 4G). There were several statistically significant correlations between lung and tumor immune compositions (Figure 4A), including a strong correlation between $\mathrm{CD} 4{ }^{+}$Th1 differentiation in adenocarcinoma as well as the nonadjacent lung parenchyma $\left(R^{2}=\right.$ 0.5050; $P<0.0001)$. This relationship between lung and tumor Th1 differentiation persisted in patients with and without COPD, and was strongest in patients with adenocarcinoma compared with squamous cell carcinoma (Figure 4D). Unexpectedly, we observed that COPDrelated changes in the lung were also present in the resected tumors; specifically, a pattern of increased tumor Th1 lymphocytes in patients with GOLD stage $1 \mathrm{COPD}$ was noted (Figure $4 \mathrm{H}$ ), recapitulating the earlier findings profiling the lung parenchyma. We also found increased expression of the immune checkpoints TIM-3 and PD- 1 on $\mathrm{CD} 4{ }^{+}$ $\mathrm{T}$ cells in tumors of patients with COPD (Figures $4 \mathrm{~K}$ and $4 \mathrm{I}$ ).

\section{The Presence of COPD Is Associated with Improved Response to ICls}

Because of the interaction between lung and increased Th1 differentiation and immune checkpoint expression seen in patients with COPD, we queried whether these findings might bear relevance to NSCLC treated with ICIs. Because very few of the patients who underwent curative-intent resection ultimately relapsed and received ICIs (3/73), we retrospectively examined a separate cohort of patients with advanced-stage NSCLC who received anti-PD-1 or anti-PD-L1 therapy. Because only a subset of these patients $(38 / 125)$ had documented spirometry, we used a clinical diagnosis of COPD and available CT imaging and spirometry to define the COPD and nonCOPD subcohorts. The patients with and without COPD were similar, with the notable exceptions that patients with COPD were slightly older and had greater cigarette smoke exposure $(45.9+27.9$ vs. $22.1+28.6$ pack-years; $P<0.0001)$. Patients with COPD received, on average, more doses of ICIs (Table 2).

We compared OS and PFS, and found that patients with COPD displayed increased PFS (153 vs. 54 days, $\log$-rank $P=$ 0.0168 ; Figure $5 \mathrm{~A}$ ) with no changes in OS (Figure 5B). Similarly, smoking status was also associated with PFS, with current smokers having significantly longer PFS tumor microenvironments and the

Figure 3. (Continued). for each group. (U) Representative hematoxylin and eosin-stained 10X light microscopy image from a smoke-exposed versus a control mouse. (K) Representative dot plot of IL-17A ${ }^{+}$staining on $\mathrm{CD}^{+}$-gated lymphocytes. The fold change in the fraction of $(L) C D 3^{+},(M) \mathrm{CD}^{+}$, and $(M)$ Th17 lymphocytes was stratified by smoke exposure. Bars denote the mean \pm SEM. ${ }^{\star} P<0.05 ;{ }^{\star \star} P<0.01 ;{ }^{* \star} P<0.001$. BV605 $=$ brilliant violet 605 (fluorochrome); ns = not significant; SCC-A = side scatter area; Treg = regulatory $\mathrm{T}$ cell. 
A

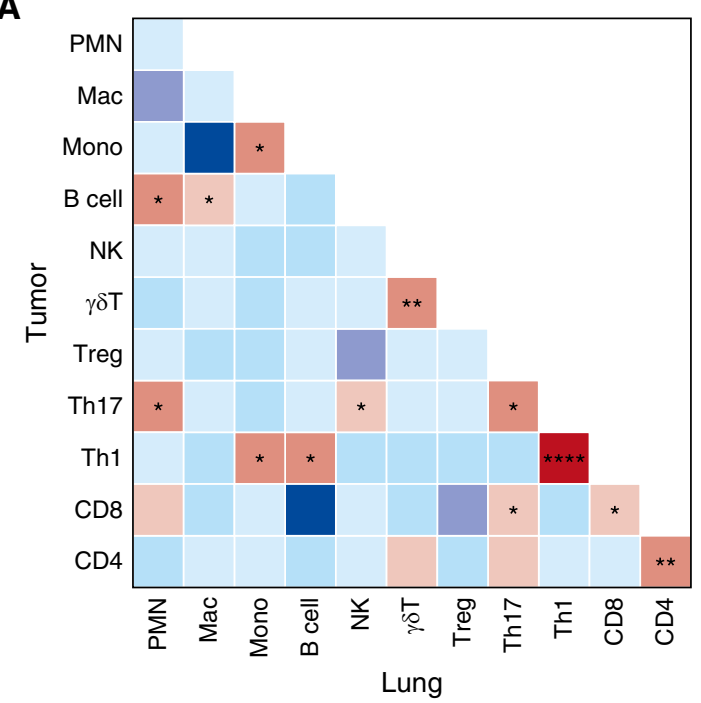

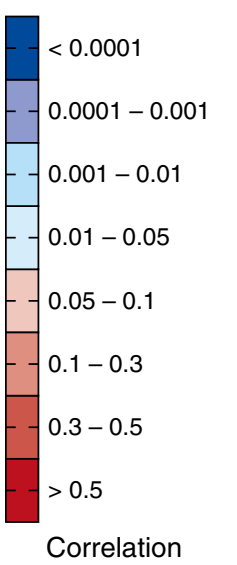

$\left(R^{2}\right)$
B

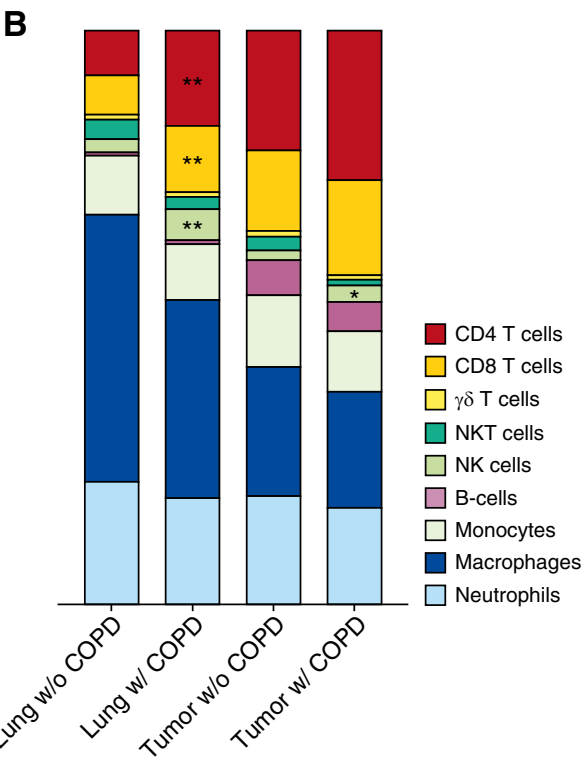

E
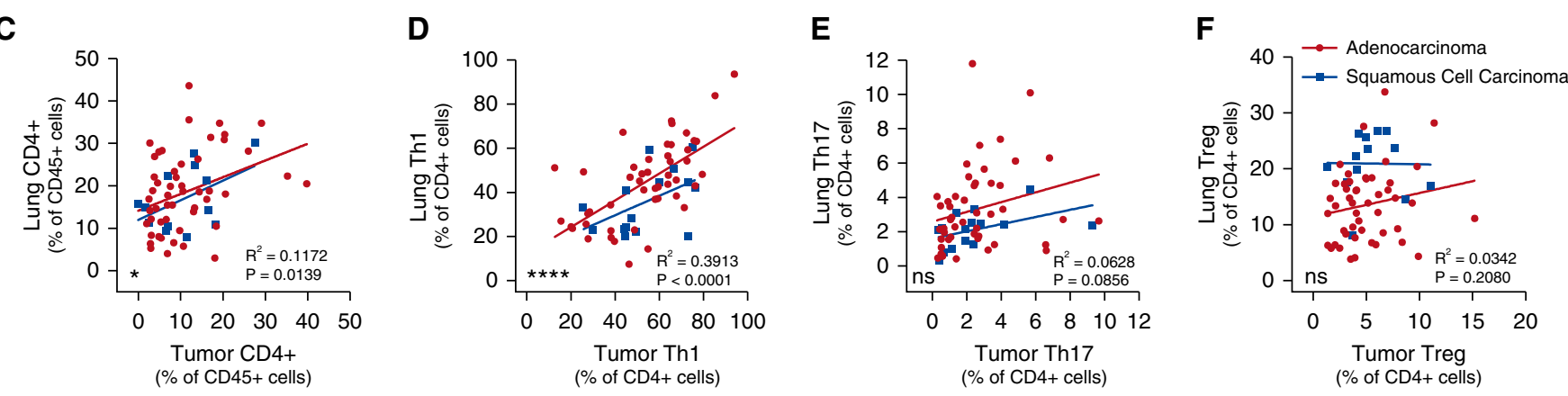

G

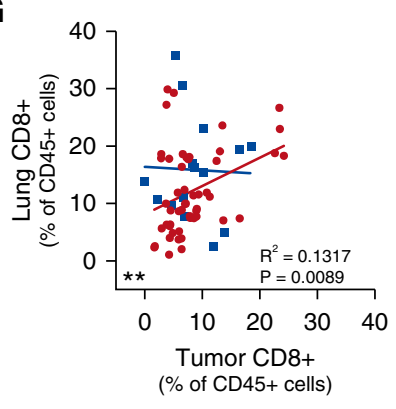

H

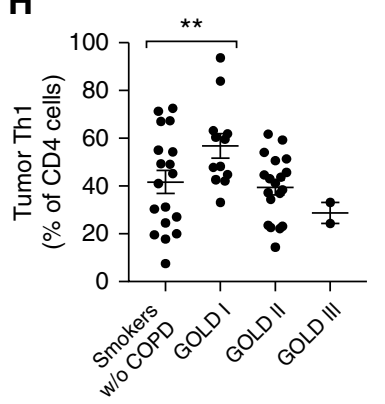

I
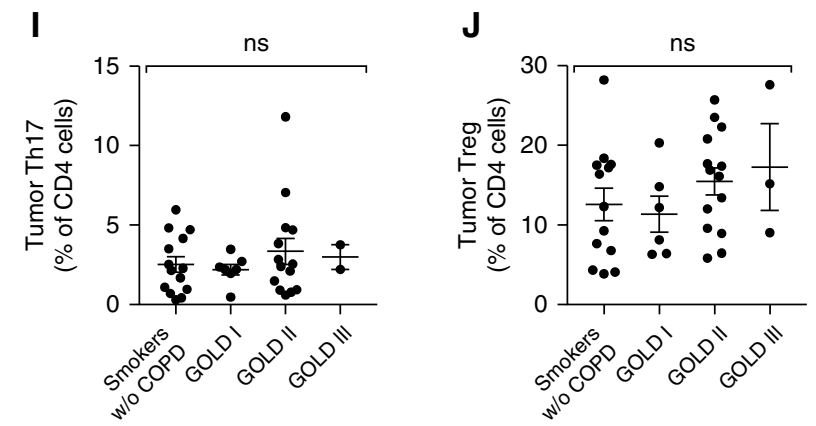

$\mathbf{L}$

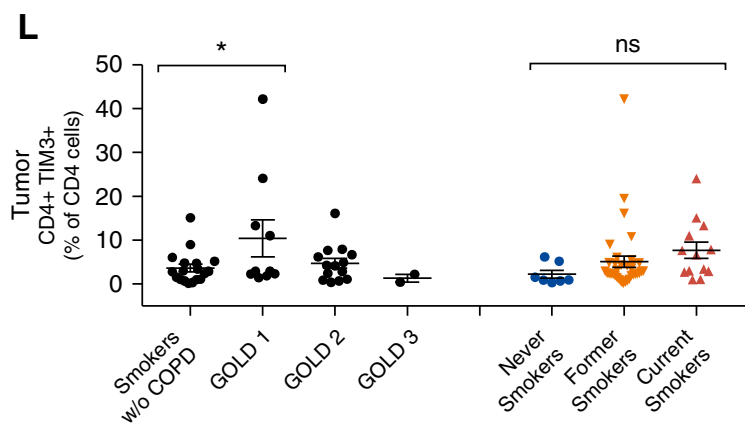

Figure 4. CD4 immunity permeates lung and tumor environments. (A) Heatmap of correlation between lung versus tumor immune cell populations. (B) Popsicle chart of mean immune cell populations in lung and tumor stratified by chronic obstructive pulmonary disease (COPD) status. (C-G) Linear regressions between lung and tumor cell counts for $\mathrm{CD}^{+}(C)$, T-helper cell type 1 (Th1) $(D)$, Th17 $(E)$, Treg $(F)$, and CD8 ${ }^{+}(G)$ cells. The red line indicates lung adenocarcinoma, and the blue line indicates squamous cell carcinoma. $(H-J)$ Tumor immune cell content of Th1 $(H)$, Th17 (I), and Treg $(J)$ cells 
Table 2. Characteristics of Cohort 2

\section{All Patients}

\section{Patients without COPD}

Patients with COPD

$P$ Value

\section{Demographics}

Subjects, $n$

Sex, male, $n(\%)$

Age at diagnosis, $y r$

$\mathrm{BMl}, \mathrm{kg} / \mathrm{m}^{2}$

Coronary artery disease present, $n(\%)$

Smoking history

Never smokers, $n(\%)$

Former smokers, $n(\%)$

Current smokers, $n$ (\%)

Pack-years

Cancer histology, $n$ (\%)

Adenocarcinoma

Squamous cell carcinoma

Adenosquamous carcinoma

Large cell neuroendocrine

Poorly differentiated

Stage at diagnosis, $n(\%)$

I

II

III

Unknown/unspecified

Prior lung cancer therapies

Received prior radiation therapy, $n(\%)$

Received prior chemotherapy, $n$ (\%)

Prior lines of chemotherapy received

Immune therapies received

Stage III at ICI initiation*, $n(\%)$

Stage IV at ICI initiation*, $n(\%)$

PD-1 inhibitor (nivolumab), $n$

PD-1 inhibitor (pembrolizumab), $n$

PD-L1 inhibitor (atezolizumab, avelumab), $n$

Number of doses received

$\begin{array}{cc}125 & 65 \\ 71(56.8 \%) & 32(49.23 \%) \\ 66.4 \pm 9.1 & 64.3 \pm 10.1 \\ 24.9 \pm 5.1 & 24.7 \pm 4.1 \\ 22(17.6 \%) & 7(10.8 \%) \\ & \\ 20(16.0 \%) & 20(30.7 \%) \\ 92(73.6 \%) & 40(61.5 \%) \\ 13(10.4 \%) & 5(7.7 \%) \\ 33.4 \pm 30.5 & 22.1 \pm 28.5 \\ & \\ 91(72.8 \%) & 49(75.4 \%) \\ 25(20.0 \%) & 11(16.9 \%) \\ 2(1.6 \%) & 0(0.0 \%) \\ 1(0.8 \%) & 1(1.5 \%) \\ 3(2.4 \%) & 2(3.1 \%) \\ & \\ 3(2.6 \%) & 0(0.0 \%) \\ 4(3.4 \%) & 2(3.1 \%) \\ 23(18.4 \%) & 13(20.0 \%) \\ 88(70.4 \%) & 48(73.8 \%) \\ 7(5.6 \%) & 2(3.1 \%) \\ 77(61.6 \%) & \\ 119(95.2 \%) & 39(60.0 \%) \\ 1.77 \pm 1.18 & 61(93.8 \%) \\ 7(5.6 \%) & 1.83 \pm 1.20 \\ 117(94.4 \%) & \\ 111 & 5(7.8 \%) \\ 18 & 59(92.2 \%) \\ 4 & 54 \\ 6.5 & 10 \\ 7 & 1 \\ 7 & 5.0 \\ & \\ 7 & \end{array}$

$$
\begin{gathered}
60 \\
39(65.0 \%) \\
68.8 \pm 7.0 \\
25.2 \pm 6.0 \\
15(25.0 \%) \\
\\
0(0.0 \%) \\
52(86.67 \%) \\
8(13.3 \%) \\
45.8 \pm 27.9 \\
42(70.0 \%) \\
14(23.3 \%) \\
2(203.3 \%) \\
0(0.0 \%) \\
1(1.7 \%) \\
\\
3(5.0 \%) \\
2(3.3 \%) \\
10(16.7 \%) \\
4066.7 \%) \\
5(8.3 \%) \\
38(63.3 \%) \\
58(96.7 \%) \\
1.70 \pm 1.16 \\
2(3.3 \%) \\
58(96.7 \%) \\
57 \\
8 \\
3 \\
8.9
\end{gathered}
$$

0.1085

0.0146

0.5921

0.0585

$<0.0001$

$<0.0001$

0.3089

0.9334

0.5684

0.4402

0.0151

Definition of abbreviations: $\mathrm{BMI}=$ body mass index; $\mathrm{COPD}=$ chronic obstructive pulmonary disease; $\mathrm{ICl}=$ immune checkpoint inhibitor; $\mathrm{NSCLC}=$ non-small cell lung cancer; PD-1 = programmed cell death protein 1; PD-L1 = programmed cell death protein ligand 1.

Data are presented as mean \pm SD unless otherwise indicated. Characteristics of the patients with NSCLC who received ICls. Comparisons were made using either Fisher's test or Student's $t$ test as appropriate. $n=125$ patients. $P$ values $<0.05$ are set in bold for emphasis.

${ }^{*}$ For one patient, the stage at the time of $\mathrm{ICl}$ initiation was not clearly documented.

than former or never smokers (Figures 5C and 5D). In univariate regression modeling (Table 3), smoking status, dose of cigarette exposure (pack-years), and the presence of COPD were the most significant factors associated with PFS in patients with NSCLC treated with ICIs. In multivariate regression modeling (Table 3 ) of body mass index, the presence of coronary artery disease, NSCLC stage at time of treatment, smoking status (current smokers vs. former/never smokers), and presence of COPD, only COPD remained significant (hazard ratio [HR], 0.58; confidence interval [CI], 0.34-0.95; $P=0.033$ ), suggesting that the presence of smokingrelated lung disease is an important modifier of the response to immune checkpoint blockade. Furthermore, when we examined the subset of $n=92$ patients who were all former smokers, we found that those who had COPD had increased PFS (154 vs. 44 d; $P=0.0491$; Figure 5E) and $O S$ ( 359 vs. 145 d; $P=0.0350$; Figure 5F) compared with patients without COPD, once again highlighting the association between the presence of COPD and the response to ICI treatment.

\section{Discussion}

Together, COPD and NSCLC represent a substantial disease burden and are clearly linked beyond just cigarette smoke exposure. Given the prominent role of the immune system in both diseases and the emergence of immune-based therapies for patients with NSCLC, we took a systematic approach, comprised of four components, to study the detailed interrelationships between COPD and lung tumor immunity. First, we identified the immune cell composition in lung tissue as a function of

Figure 4. (Continued). stratified by Global Initiative for Chronic Obstructive Lung Disease (GOLD) stage. (A-J) For lung-tumor relationships, $n=64$ non-small cell lung cancer, $n=51$ lung adenocarcinoma patients, and $n=13$ squamous cell carcinoma patients. $(K$ and $L)$ Expression of PD- $1^{+}(K)$ and $\mathrm{TIM}^{+} 3^{+}(L)$ immune checkpoints on tumor-derived CD4 $4^{+}$cells; $n=44$ lung adenocarcinoma patients as a function of smoking and COPD status. Bars denote the mean \pm SEM. ${ }^{\star} P<0.05 ;{ }^{* \star} P<0.01 ;{ }^{* \star *} P<0.0001$. mac $=$ macrophage; mono = monocyte; NK = natural killer; NKT = natural killer T-cell; ns = not significant; PD-1 = programmed cell death protein 1; PMN = polymorphonuclear leukocytes; TIM-3 = T-cell immunoglobin and mucin-domain containing-3; Treg = regulatory $\mathrm{T}$ cell; $\mathrm{w} / \mathrm{O}=$ without. 
A

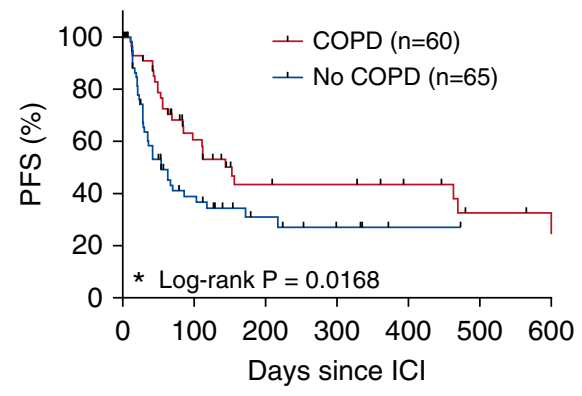

B

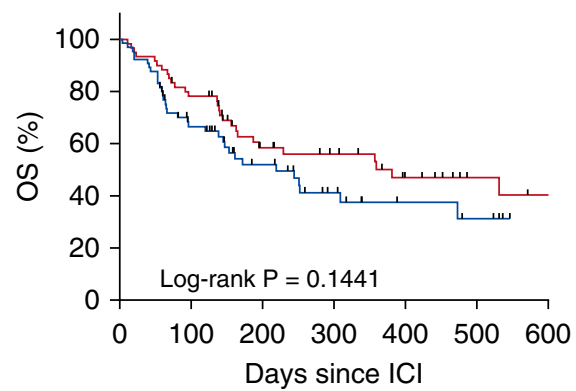

C

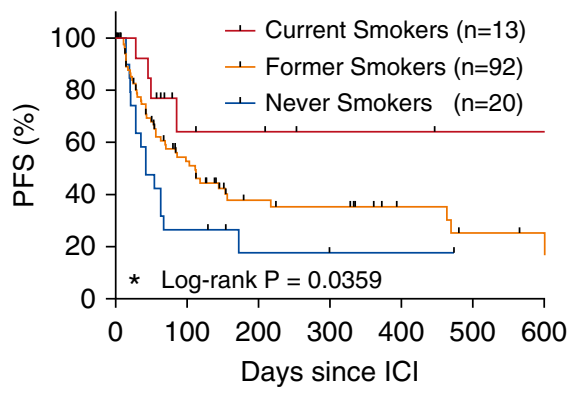

D

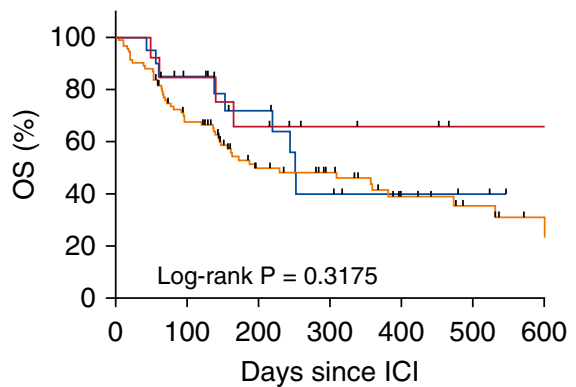

E

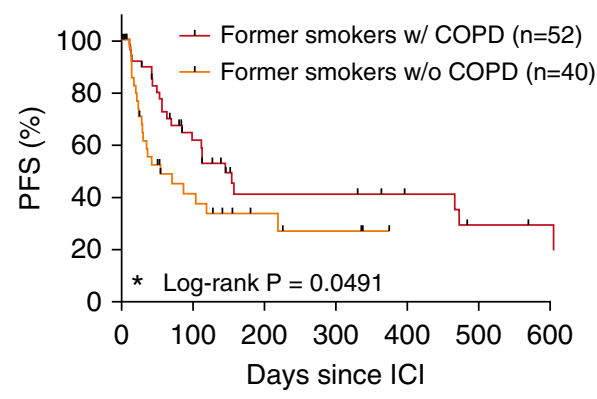

$\mathbf{F}$

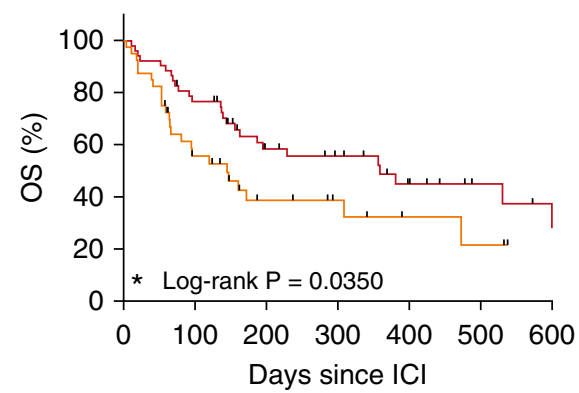

Figure 5. Effect of chronic obstructive pulmonary disease (COPD) and smoking status on survival in patients with non-small cell lung cancer treated with immune checkpoint inhibitors (ICls). Shown are Kaplan-Meier curves comparing the progression-free survival (PFS) and overall survival (OS) from initiation of $\mathrm{ICl}$ therapy in patients with non-small cell lung cancer, analyzed by the presence of COPD $(A$ and $B)$ and by smoking status $(C$ and $D)$, and among former smokers with or without COPD ( $E$ and $F$ ). $n=125$ patients in $A-D$ and 92 patients in $E$ and $F$. ${ }^{*} P<0.05$. w/o $=$ without.

COPD severity. Second, we examined the interrelationships between the immune cell content in COPD tissue and NSCLC tissue from matched patients. Third, we examined the impact of COPD severity on tumor immunity. Finally, we assessed the impact of the presence of COPD on the outcome of ICI therapy for patients with NSCLC.

We found compelling evidence that there are several distinct subphenotypes of COPD with various immune profiles, and identified a marked increase in both $\mathrm{CD} 4^{+}$ cellular content and Th1 polarization in COPD. Importantly, the data presented here provide the first evidence that the presence of COPD predicts a favorable treatment response to immune checkpoint inhibition for NSCLC. Additional studies will be required to determine whether the prominent Th1 signature transcending COPD and NSCLC microenvironments is responsible for the observed treatment effects. The effect of COPD on ICI efficacy has not been previously reported, and the effect of PD-1/PD-L1 blockade on COPD is also unknown. It is clear that current or former smokers are more likely to respond to therapy with PD-1 inhibitors (26-29), possibly due to an increased mutational burden in their tumors from prolonged carcinogen (cigarette) exposure (36). We found that the presence of COPD (in addition to smoking status) significantly improved the response to ICI treatment. This is counterintuitive because the presence of COPD is known to worsen survival in patients with lung cancer (5-7, 12). This novel and unexpected finding, coupled with the observation that the tumor microenvironment recapitulates that of the lung, may have important therapeutic implications for patient selection and predicting response to therapy. Further prospective trials are needed to better characterize the relationship between COPD and ICI efficacy.

Based on prior reports that Th17 cytokines play prominent roles in both diseases $(37,38)$, our original hypothesis was that Th17 immunity would link COPD and NSCLC. Surprisingly, we found that Th17 correlated with smoking status, but not with COPD presence or progression. Five prior human studies $(17,18,39-41)$, backed by experimental data in mice (16, $38,42-44)$, identified increased numbers of IL-17A ${ }^{+} \mathrm{T}$ cells in the lungs of patients with COPD compared with nonsmoking controls. However, our results suggest that increases in IL-17A ${ }^{+}$lymphocytes may be a marker for recent smoke exposure, but not for COPD per se. Certainly, IL-17 cytokines appear to contribute to cigarette smoke-induced emphysema, as inhibiting this axis limits disease progression in mice (16). However, our results suggest that Th17 cells may play a limited role in former smokers. This finding has important clinical ramifications, as IL-17 antagonism has been proposed for both COPD therapy and lung cancer chemoprophylaxis.

In line with prior studies $(19,45)$, we found increased numbers of IFN-

$\gamma$-producing $\mathrm{CD}^{+}$lymphocytes, both in patients with mild airflow obstruction and in patients with emphysema, suggesting that these cells may also be involved in the pathogenesis of COPD. Despite evidence that clonal $\mathrm{T}$ cell populations are responsible for the pathogenesis of COPD, and in contrast to some prior studies $(22,23,46)$, we did not identify increased rearrangements of particular TCR- $\beta$ gene loci, nor did we find specific TCR- $\beta$ sequences to be associated with COPD. Some previous studies used ex vivo expanded lymphocyte populations (22), which may explain the differences in results. 
Table 3. Predictors of Progression-Free Survival in Patients Treated with Immune Checkpoint Inhibitors

$\begin{array}{lll}\text { Characteristics } & \text { HR (95\% Cl) } & P \text { Value } \\ \text { Univariate predictors of PFS } & & \\ \text { Sex, M } & 0.92(0.56-1.51) & 0.733 \\ \text { Age, per 1 yr* } & 1.00(0.97-1.03) & 0.94 \\ \text { Tumor histology (adenocarcinoma vs. squamous } & 1.06(0.60-1.92) & 0.82 \\ \quad \text { cell carcinoma) } & & \\ \text { Prior radiation therapy } & 0.91(0.55-1.49) & 0.70 \\ \text { Prior chemotherapy (per line of therapy) } & 1.15(0.91-1.43) & 0.24 \\ \text { History of CAD } & 0.79(0.41-1.56) & 0.509 \\ \text { BMI } & & \\ \text { Normal vs. underweight } & 0.47(0.11-1.96) & 0.304 \\ \text { Normal vs. overweight } & 0.67(0.37-1.20) & 0.176 \\ \text { Normal vs. obese } & 0.49(0.24-1.02) & 0.058 \\ \text { Smoking status } & & \\ \text { Former smoker vs. never smoker } & 0.63(0.35-1.15) & 0.14 \\ \text { Current vs. never smoker } & 0.28(0.09-0.84) & \mathbf{0 . 0 2 4} \\ \text { Ever smoker vs. never smoker } & 0.40(0.15-1.10) & 0.077 \\ \text { Pack-years smoked (per pack-year) } & 0.99(0.98-1.00) & 0.014 \\ \text { COPD } & 0.56(0.34-0.93) & \mathbf{0 . 0 2 4} \\ \text { Multivariate predictors of PFS } & & \\ \text { Smoking status: current smokers } & 0.42(0.15-1.16) & 0.097 \\ \text { COPD } & 0.57(0.35-0.96) & \mathbf{0 . 0 3 3}\end{array}$

Definition of abbreviations: $\mathrm{BMI}=$ body mass index; $\mathrm{CAD}=$ coronary artery disease; $\mathrm{Cl}$ = confidence interval; COPD = chronic obstructive pulmonary disease; $\mathrm{HR}=$ hazard ratio; $\mathrm{PFS}=$ progression-free survival.

Factors associated with prolonged PFS in univariate and multivariate Cox proportional hazards models $(n=$ 125 patients). The HR (95\% Cl) and $P$ value are shown for each. $P$ values $<0.05$ are set in bold for emphasis. *Additional risk with each additional year of age.

In contrast to prior studies, we did not find evidence of alterations in immune checkpoint expression associated with cigarette smoke exposure, airflow obstruction, or emphysema.

Recently, McKendry and colleagues (21) and Kalathil and colleagues (20) found an increase in the fraction of PD- $1^{+} \mathrm{CD} 4^{+}$cells in circulating lymphocytes of patients with COPD versus healthy controls. To determine a more direct effect of immune checkpoint expression, we investigated the prognostic significance of the altered immune phenotype of COPD in patients who had received ICIs, and found that smoking status and the presence of COPD were associated with PFS in patients treated with ICIs.
There were three notable limitations to our study. First, because all of the patients in our cohort were undergoing resection of lung cancer, it is possible that the presence of malignancy affected the immune milieu of the lung. However, because we were interested in the immune interactions between NSCLC and COPD, this was unavoidable. Second, the immune profiling analysis was not performed on the cohort of patients who received ICI therapy. Ideally, we would have performed the immune cell analysis on lung tissue derived from ICI recipients. Unfortunately, just 3 of 73 patients in the lung cancer resection cohort ultimately received ICI therapy, and few patients with advanced-stage NSCLC (those who typically receive ICI therapy) have a clinical indication for lung tissue resection. Therefore, although our study was limited by the use of two cohorts instead of one, fresh lung tissue is seldom available from any cohort of ICI recipients. Third, lung tissue from unaffected patients was not used as a control. Unfortunately, there is no clinical situation in which surgically resected lung tissue would be available for research in the absence of a disease process that would potentially perturb lung immunity (such as infection or cancer). Given the inherent difficulties of obtaining sufficient fresh human lung tissue, most prior studies used either blood or BAL samples. The results of those studies and ours are comparable in that they suggest that $\mathrm{CD}^{+}$- and Th1-mediated immunity drives COPD progression, although other studies have found a more important role for Th17, as discussed above.

The current study represents the largest flow-cytometric assessment of COPD and NSCLC tissue immune cell content to date. Among patients with surgically resected NSCLC, we identified a novel Th1 signature in the lung tissue of patients with COPD that permeated the tumor microenvironment. Furthermore, in patients with more advanced NSCLC, the presence of COPD was associated with enhanced efficacy of ICIs, a novel finding that may have important prognostic implications for patients with NSCLC treated with immune therapies.

Author disclosures are available with the text of this article at www.atsjournals.org.

Acknowledgments: The authors thank Sara Daniel at Northwest BioTrust for assistance with obtaining human samples, the Fred Hutchinson Cancer Research Center Flow Cytometry Core Facility for assistance with the flow-cytometry studies, and Adaptive Biotechnologies for assistance with the analysis of TCR- $\beta$ sequencing data.

\section{References}

1. Barnes PJ. Immunology of asthma and chronic obstructive pulmonary disease. Nat Rev Immunol 2008;8:183-192.

2. Houghton AM, Mouded M, Shapiro SD. Common origins of lung cancer and COPD. Nat Med 2008;14:1023-1024.

3. Houghton AM. Mechanistic links between COPD and lung cancer. Nat Rev Cancer 2013;13:233-245.

4. Skillrud DM, Offord KP, Miller RD. Higher risk of lung cancer in chronic obstructive pulmonary disease. A prospective, matched, controlled study. Ann Intern Med 1986;105:503-507.
5. Tockman MS, Anthonisen NR, Wright EC, Donithan MG. Airways obstruction and the risk for lung cancer. Ann Intern Med 1987;106:512-518.

6. Speizer FE, Fay ME, Dockery DW, Ferris BG Jr. Chronic obstructive pulmonary disease mortality in six U.S. cities. Am Rev Respir Dis 1989;140:S49-S55.

7. Lange P, Nyboe J, Appleyard M, Jensen G, Schnohr P. Ventilatory function and chronic mucus hypersecretion as predictors of death from lung cancer. Am Rev Respir Dis 1990;141:613-617.

8. Wilson DO, Weissfeld JL, Balkan A, Schragin JG, Fuhrman CR, Fisher SN et al. Association of radiographic emphysema and airflow obstruction with lung cancer. Am J Respir Crit Care Med 2008;178:738-744. 
9. Maldonado F, Bartholmai BJ, Swensen SJ, Midthun DE, Decker $P A$, Jett JR. Are airflow obstruction and radiographic evidence of emphysema risk factors for lung cancer? A nested case-control study using quantitative emphysema analysis. Chest 2010;138: 1295-1302.

10. de Torres JP, Bastarrika G, Wisnivesky JP, Alcaide AB, Campo A, Seijo $\mathrm{LM}$, et al. Assessing the relationship between lung cancer risk and emphysema detected on low-dose CT of the chest. Chest 2007;132: 1932-1938.

11. Li Y, Swensen SJ, Karabekmez LG, Marks RS, Stoddard SM, Jiang R, et al. Effect of emphysema on lung cancer risk in smokers: a computed tomography-based assessment. Cancer Prev Res (Phila) 2011;4:43-50.

12. Zulueta JJ, Wisnivesky JP, Henschke CI, Yip R, Farooqi AO, McCauley $\mathrm{DI}$, et al. Emphysema scores predict death from COPD and lung cancer. Chest 2012;141:1216-1223.

13. Punturieri A, Szabo E, Croxton TL, Shapiro SD, Dubinett SM. Lung cancer and chronic obstructive pulmonary disease: needs and opportunities for integrated research. J Natl Cancer Inst 2009;101: 554-559.

14. Hogg JC, Chu F, Utokaparch S, Woods R, Elliott WM, Buzatu L, et al. The nature of small-airway obstruction in chronic obstructive pulmonary disease. N Engl J Med 2004;350:2645-2653.

15. Grumelli S, Corry DB, Song LZ, Song L, Green L, Huh J, et al. An immune basis for lung parenchymal destruction in chronic obstructive pulmonary disease and emphysema. PLoS Med 2004;1:e8.

16. Chen K, Pociask DA, McAleer JP, Chan YR, Alcorn JF, Kreindler JL, et al. IL-17RA is required for CCL2 expression, macrophage recruitment, and emphysema in response to cigarette smoke. PLOS One 2011;6:e20333.

17. Zhang J, Chu S, Zhong X, Lao Q, He Z, Liang Y. Increased expression of CD4+IL-17+ cells in the lung tissue of patients with stable chronic obstructive pulmonary disease (COPD) and smokers. Int Immunopharmacol 2013;15:58-66.

18. Roos AB, Sandén C, Mori M, Bjermer L, Stampfli MR, Erjefält JS. IL-17A is elevated in end-stage chronic obstructive pulmonary disease and contributes to cigarette smoke-induced lymphoid neogenesis. Am J Respir Crit Care Med 2015;191:1232-1241.

19. Freeman CM, Han MK, Martinez FJ, Murray S, Liu LX, Chensue SW, et al. Cytotoxic potential of lung CD8(+) T cells increases with chronic obstructive pulmonary disease severity and with in vitro stimulation by IL-18 or IL-15. J Immunol 2010;184: 6504-6513.

20. Kalathil SG, Lugade AA, Pradhan V, Miller A, Parameswaran GI, Sethi S, et al. T-regulatory cells and programmed death $1+\mathrm{T}$ cells contribute to effector T-cell dysfunction in patients with chronic obstructive pulmonary disease. Am J Respir Crit Care Med 2014; 190:40-50.

21. McKendry RT, Spalluto CM, Burke $H$, Nicholas B, Cellura D, Al-Shamkhani A, et al. Dysregulation of antiviral function of CD8(+) T cells in the chronic obstructive pulmonary disease lung. Role of the PD-1-PD-L1 axis. Am J Respir Crit Care Med 2016;193: 642-651.

22. Sullivan AK, Simonian PL, Falta MT, Mitchell JD, Cosgrove GP, Brown KK, et al. Oligoclonal CD4 + T cells in the lungs of patients with severe emphysema. Am J Respir Crit Care Med 2005;172: 590-596.

23. Motz GT, Eppert BL, Sun G, Wesselkamper SC, Linke MJ, Deka R, et al. Persistence of lung CD8 T cell oligoclonal expansions upon smoking cessation in a mouse model of cigarette smoke-induced emphysema. J Immunol 2008;181:8036-8043.

24. Bremnes RM, Busund LT, Kilvær TL, Andersen S, Richardsen E, Paulsen EE, et al. The role of tumor-infiltrating lymphocytes in development, progression, and prognosis of non-small cell lung cancer. J Thorac Oncol 2016;11:789-800.

25. Gooden MJ, de Bock GH, Leffers N, Daemen T, Nijman HW. The prognostic influence of tumour-infiltrating lymphocytes in cancer: a systematic review with meta-analysis. Br J Cancer 2011; 105:93-103.
26. Borghaei H, Paz-Ares L, Horn L, Spigel DR, Steins M, Ready NE, et al. Nivolumab versus docetaxel in advanced nonsquamous non-smallcell lung cancer. N Engl J Med 2015;373:1627-1639.

27. Brahmer J, Reckamp KL, Baas P, Crinò L, Eberhardt WE, Poddubskaya E, et al. Nivolumab versus docetaxel in advanced squamous-cell nonsmall-cell lung cancer. N Engl J Med 2015;373:123-135.

28. Reck M, Rodríguez-Abreu D, Robinson AG, Hui R, Csőszi T, Fülöp A et al.; KEYNOTE-024 Investigators. Pembrolizumab versus chemotherapy for PD-L1-positive non-small-cell lung cancer. N Engl J Med 2016;375:1823-1833.

29. Garon EB, Rizvi NA, Hui R, Leighl N, Balmanoukian AS, Eder JP, et al.; KEYNOTE-001 Investigators. Pembrolizumab for the treatment of non-small-cell lung cancer. N Engl J Med 2015;372: 2018-2028.

30. Kargl J, Busch SE, Yang GH, Kim KH, Hanke ML, Metz HE, et al. Neutrophils dominate the immune cell composition in non-small cell lung cancer. Nat Commun 2017;8:14381.

31. Vestbo J, Hurd SS, Agustí AG, Jones PW, Vogelmeier C, Anzueto A, et al. Global strategy for the diagnosis, management, and prevention of chronic obstructive pulmonary disease: GOLD executive summary. Am J Respir Crit Care Med 2013;187:347-365.

32. Goddard PR, Nicholson EM, Laszlo G, Watt I. Computed tomography in pulmonary emphysema. Clin Radiol 1982;33:379-387.

33. Hautamaki RD, Kobayashi DK, Senior RM, Shapiro SD. Requirement for macrophage elastase for cigarette smoke-induced emphysema in mice. Science 1997;277:2002-2004.

34. Busch SE, Hanke ML, Kargl J, Metz HE, MacPherson D, Houghton AM. Lung cancer subtypes generate unique immune responses. $J$ Immunol 2016;197:4493-4503.

35. Sallusto F, Lenig D, Förster R, Lipp M, Lanzavecchia A. Two subsets of memory $\mathrm{T}$ lymphocytes with distinct homing potentials and effector functions. Nature 1999;401:708-712.

36. Rizvi NA, Hellmann MD, Snyder A, Kvistborg P, Makarov V, Havel JJ, et al. Cancer immunology. Mutational landscape determines sensitivity to PD-1 blockade in non-small cell lung cancer. Science 2015;348:124-128.

37. Chang SH, Mirabolfathinejad SG, Katta H, Cumpian AM, Gong L, Caetano MS, et al. T helper 17 cells play a critical pathogenic role in lung cancer. Proc Natl Acad Sci USA 2014;111:5664-5669.

38. Shan M, Yuan X, Song LZ, Roberts L, Zarinkamar N, Seryshev A, et al. Cigarette smoke induction of osteopontin (SPP1) mediates $\mathrm{T}(\mathrm{H}) 17$ inflammation in human and experimental emphysema. Sci Transl Med 2012;4:117ra9.

39. Eustace A, Smyth LJC, Mitchell L, Williamson K, Plumb J, Singh D. Identification of cells expressing IL-17A and IL-17F in the lungs of patients with COPD. Chest 2011;139:1089-1100.

40. Di Stefano A, Caramori G, Gnemmi I, Contoli M, Vicari C, Capelli A, et al. T helper type 17-related cytokine expression is increased in the bronchial mucosa of stable chronic obstructive pulmonary disease patients. Clin Exp Immunol 2009;157:316-324.

41. Doe C, Bafadhel M, Siddiqui S, Desai D, Mistry V, Rugman $P$, et al. Expression of the T helper 17-associated cytokines IL-17A and IL-17F in asthma and COPD. Chest 2010;138:1140-1147.

42. Shen N, Wang J, Zhao M, Pei F, He B. Anti-interleukin-17 antibodies attenuate airway inflammation in tobacco-smoke-exposed mice. Inhal Toxicol 2011;23:212-218.

43. Chang Y, Al-Alwan L, Audusseau S, Chouiali F, Carlevaro-Fita J, Iwakura Y, et al. Genetic deletion of IL-17A reduces cigarette smokeinduced inflammation and alveolar type II cell apoptosis. Am J Physiol Lung Cell Mol Physiol 2014;306:L132-L143.

44. Kurimoto E, Miyahara N, Kanehiro A, Waseda K, Taniguchi A, Ikeda G, et al. IL-17A is essential to the development of elastase-induced pulmonary inflammation and emphysema in mice. Respir Res 2013;14:5.

45. Maeno T, Houghton AM, Quintero PA, Grumelli S, Owen CA, Shapiro SD. CD8 + T cells are required for inflammation and destruction in cigarette smoke-induced emphysema in mice. J Immunol 2007;178:8090-8096.

46. Korn S, Wiewrodt R, Walz YC, Becker K, Mayer E, Krummenauer F, et al. Characterization of the interstitial lung and peripheral blood T cell receptor repertoire in cigarette smokers. Am J Respir Cell Mol Biol 2005;32:142-148. 